\title{
Ambiguity and vagueness in historical change
}

Link to publication record in Manchester Research Explorer

\section{Citation for published version (APA):}

Denison, D. (2017). Ambiguity and vagueness in historical change. In M. Hundt, S. Mollin, \& S. E. Pfenninger (Eds.), The changing English language: Psycholinguistic perspectives (pp. 292-318). (Studies in English Language). Cambridge University Press.

\section{Published in:}

The changing English language

\section{Citing this paper}

Please note that where the full-text provided on Manchester Research Explorer is the Author Accepted Manuscript or Proof version this may differ from the final Published version. If citing, it is advised that you check and use the publisher's definitive version.

\section{General rights}

Copyright and moral rights for the publications made accessible in the Research Explorer are retained by the authors and/or other copyright owners and it is a condition of accessing publications that users recognise and abide by the legal requirements associated with these rights.

\section{Takedown policy}

If you believe that this document breaches copyright please refer to the University of Manchester's Takedown Procedures [http://man.ac.uk/04Y6Bo] or contact uml.scholarlycommunications@manchester.ac.uk providing relevant details, so we can investigate your claim.

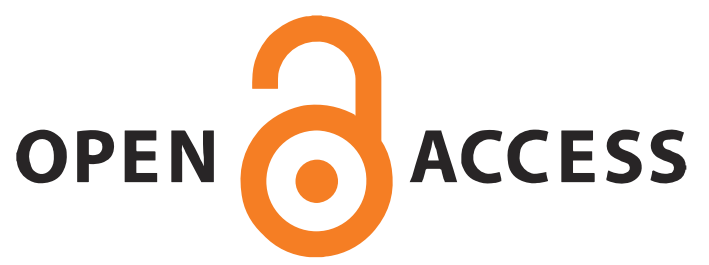


13

\section{Ambiguity and vagueness in historical change ${ }^{1}$}

David Denison

\section{Introduction: incomplete knowledge}

\subsection{Participants}

This chapter concerns the role of incomplete knowledge in linguistic change, particularly on the part of an addressee/reader (AD/R). I will argue that speaker/writer (SP/W) may sometimes lack complete knowledge too. In addition, of course, the linguist rarely has complete knowledge either. What is not known may have a bearing on appropriate theories of language. I begin with a brief look at the difference between the (un)knowns of historical linguists and psycholinguists as observer-participants in acts of linguistic communication.

In historical linguistics, where written data is still the norm, a linguist $\mathrm{R}$ is a little different from the original readership envisaged by $\mathrm{W}$ : potentially more knowledgeable in some ways, whether by virtue of hindsight or specialist knowledge, but then again perhaps ignorant of cultural and pragmatic facts obvious to a contemporary reader. For recent audio broadcast or telephone data, the historical linguist is much like a normal AD, except that (s)he can listen repeatedly to a sound clip. With spoken conversational data, non-verbal cues are usually lacking. In broad terms, however, the historical linguist is simulating being $\mathrm{AD} / \mathrm{R}$ of an individual act of linguistic communication and - in corpus linguistics - generalising across many such acts.

\footnotetext{
${ }^{1}$ I am particularly grateful to Anne Curzan as well as to the editors for helpful comments on a first draft.
} 
A psycholinguist, on the other hand, does not resemble $\mathrm{AD} / \mathrm{R}$ but is rather an intimate external observer of the SP/W-AD/R dyad. Linguistic situations are contrived experimentally in order to get data which might not occur in normal life, or at least not well enough controlled or with sufficient frequency for good statistics. Psycholinguists also look in detail at the processes involved in $\mathrm{AD} / \mathrm{R}$ 's reception and sometimes SP's (rarely W's) production.

\subsection{Ambiguity vs. vagueness}

I distinguish two kinds of incomplete knowledge. Ambiguity is where $\mathrm{AD} / \mathrm{R}$ (and linguist) cannot be sure which of two or more linguistic possibilities was intended by SP/W, and something hangs on the choice. Vagueness is where a linguistic analysis is in some relevant respect underdetermined at least for $\mathrm{AD} / \mathrm{R}$ (perhaps for $\mathrm{SP} / \mathrm{W}$ too), but no further information is needed for interpretation. The distinction is a familiar one in lexical semantics, and later in this chapter I will extend it to other linguistic domains such as syntactic structure and lexeme boundaries.

What differentiates ambiguity from vagueness is whether or not SP/W could have made a choice, and furthermore, whether such a choice would have mattered. Since neither the existence nor the importance of a choice are wholly clear-cut notions, there could in principle be some middle ground between ambiguity and vagueness; one such case is noted in Section 2.1.

Lexical ambiguity is easy to illustrate. It can be the outcome of divergence between senses of a polysemous word, or it may be due to accidental homonymy, as with bank 'financial institution' vs. 'ground bordering a river' (see here OED s.vv. bank n. ${ }^{1}$ and n. ${ }^{3}$ ). The word 
bank in the second clause of (1), which directly follows a sentence mentioning the River Nile, is in principle ambiguous:

(1) When Ethiopia sought World Bank financing for this dam more than 20 years ago, the U.S. leaned on the bank to say no. (2013, via WebCorp)

Of course in practice there is no real doubt in this case. Although lexical ambiguity can be striking and may sometimes be implicated in semantic change, it is not a prerequisite, whereas vagueness often is, as we will see in Section 2.

Vagueness is a trickier concept. It is difficult to restrict in a systematic way what is underdetermined in a given instance of vagueness. Traugott \& Trousdale (2013: 199) use a more practical definition of vagueness in lexical semantics, "blended, simultaneously present subcases of a more general meaning", which can be extended to other domains.

With ambiguity there is a risk of choosing the 'wrong' reading. A mistake may subsequently become apparent to $\mathrm{AD} / \mathrm{R}$; for example, 'garden-path' sentences suggest a reading that comes to a dead end as more of the utterance is processed, in principle forcing $\mathrm{AD} / \mathrm{R}$ to backtrack and explore an alternative analysis. A priori, vagueness should be less costly than ambiguity, as there is no need for $\mathrm{AD} / \mathrm{R}$ to backtrack and try again. However, there is some evidence from psycholinguistics that in practice $\mathrm{AD} / \mathrm{R}$ 's are reluctant to backtrack and may stick with the wrong reading, even at the cost of contradiction (Felser this volume). With vagueness there is no 'wrong' reading (though of course an AD can choose to ask SP to be more specific).

In subsequent sections we look at how ambiguity and vagueness play out diachronically in a number of different linguistic domains. I will argue that in many cases greater weight should 
be given to vagueness than ambiguity as a driver of change, and consequently that tolerance of vagueness is necessary for realistic linguistic analyses.

\section{Semantic change}

A particular context may invite a reinterpretation of the meaning of a word or expression. Numerous accounts of semantic change invoke such a starting-point, generally locating the novel contextual meaning in the pragmatics of the utterance rather than the semantics of the individual expression. The idea is that repeated association with that context may lead to the new sense becoming part of the semantics, no longer dependent on the particular context. The old sense remains - at least to begin with - beside the new, and the resulting polysemy often persists.

Details and emphasis vary between scholars. One approach looks for a mismatch between $\mathrm{SP} / \mathrm{W}$ 's and $\mathrm{AD} / \mathrm{R}$ 's interpretation in a so-called 'bridging context' (Evans \& Wilkins 2000: 549-50, Diewald 2002, Heine 2002), one where either sense would fit and neither participant need be aware of any discrepancy. Vagueness in the semantics is crucial to such a process, whereas ambiguity is unlikely to recur often enough to affect the entrenchment or spread of an innovation, except as suggested in Section 2.2 below.

More elaborated is the 'Invited Inferencing Theory of Semantic Change' (Traugott 1999, Traugott \& Dasher 2002, and see also Hansen \& Waltereit 2006), an interaction of pragmatics and semantics that is applied to various expressions with an element of subjectivity. It can be summarised as follows. SP/Ws may exploit an invited inference (IIN) to add meaning to an utterance that is not, strictly speaking, derivable from the semantics of an expression. Such a one-off inference may be context-dependent, for example It's raining! 
as a request to bring the washing in, or dependent on encyclopaedic knowledge, for example the name of a country's capital city as journalistic shorthand for the national government. If such an IIN becomes conventionalised through repetition, it becomes a Generalized Invited Inference (GIIN). At this stage it is still part of pragmatics and is cancellable, but a further step may semanticise the GIIN so that it moves from pragmatics to become part of the (en)coded meaning of the expression. Thus the process as envisaged here is speaker-led, or at least intersubjective - a sort of implicit conspiracy between SP/W and AD/R. Vagueness is crucial, because only inferences that are underdetermined by the semantics can be added pragmatically.

The case studies below illustrate with dictionary and corpus evidence the development of new senses and the loss of old ones. Note that historical lexicography has tended to emphasise first and last attestations, whereas corpus linguistics sets greater store by frequency.

\subsection{Semantic vagueness and ambiguity}

The etymology of holiday in British English is transparent. The $O E D$ senses relevant for our purposes are shown in Table 1. The difference between senses 1 and 2a can be stated in terms of inherent and inferential features (Lipka 1985), with sense 1 inherently (i.e. semantically) about religion, and 'no work' an inferential feature (= contextual pragmatic inference). In sense 2a the 'no work' component has become inherent (has been semanticised) and the 'religious festival' component has been lost, while in sense $2 \mathrm{~b}$ the 'duration of one day' component has been lost as well (Leech 1981). The dictionary’s comment on sense 2a, "[i]n early use not separable from sense 1", implies that in late Middle English there were many bridging contexts where the defining characteristic of the semantics could be either the 
religious festival or the time off work or both: the features were pragmatically equivalent. It is difficult in such a case to distinguish between ambiguity and vagueness.

\begin{tabular}{|l|l|l|}
\hline sense & currency & OED definition \\
\hline 1 & OE- & $\begin{array}{l}\text { A consecrated day, a religious festival. Now usually written holy- } \\
\text { day }\end{array}$ \\
\hline $2 \mathrm{a}$ & a1400(a1325)- & {$[\ldots]$ a day of exemption or cessation from work; a day of festivity, } \\
& recreation, or amusement. \\
\hline 2b & c1400- & $\begin{array}{l}\text { collect. pl. or sing. A time or period of cessation from work, or of } \\
\text { festivity or recreation; a vacation. }\end{array}$ \\
\hline
\end{tabular}

Table 1: Some senses of holiday

Consider now passenger. We concentrate on the two senses surviving into Modern English, both probably borrowed from Anglo-Norman in the Middle English period. One is '[a] person who passes by or through a place; a traveller, esp. a traveller on foot'. It is marked by $O E D$ as obsolete and chiefly Scottish in later use (s.v., 3a, a1450-1886). In fact it survives into the twentieth century, as (2) attests:

(2) a. But other passengers were approaching Lincoln meanwhile by other roads on foot. (1919 Woolf, Night \& Day)

b. $\quad . .$. his quick walk along the streets and in and out of traffic and footpassengers (ibid.)

The other is what the $O E D$ calls 'now the usual sense', defined as '[a] person in or on a conveyance other than its driver, pilot, or crew' (s.v., 4, 1511- ). ${ }^{2}$ Both senses refer to

\footnotetext{
${ }^{2}$ A later, figurative connotation of laziness or freeloading is not explored here.
} 
travellers other than those driving or directing some form of conveyance (horse, carriage, bicycle, boat, etc.). In early use it was possible to have vague contexts which did not require the senses to be distinguished:

(3) 'It is the Watermen that cals for passengers to goe Westward now.' (1595, OED s.v. ho, int. ${ }^{1}$ )

There are 15 instances of passenger(s) in PPCMBE (948,895 words, 1700-1914), of which 14 concern people aboard ships, a context which virtually guarantees the 'conveyee' sense (though cf. (3)). The sole exception, from the play She Stoops to Conquer, is

(4) a. As you say, we passengers are to be taxed to pay all these fineries. (1773, PPCMBE)

The context is (so the speaker believes) an inn to which he and his companion in a postchaise have been directed, so either sense of passenger will fit, though contextually 'passing traveller' (sense 3a) is more likely, and indeed the companion responds:

(4)b. Travellers, George, must pay in all places ...

The 'passing traveller' (increasingly, 'traveller on foot') and 'conveyee' senses move far enough apart to permit at least theoretical ambiguity:

(5) The police believe they have a clue to the man who placed the nitro-glycerine which last night blew up a Euclid Avenue car and injured four passengers. (1899, COHA) Four people in the car or four passers-by? - the difference matters. The 'conveyee' sense is a relationship word, implicating the existence of a conveyance. Conversely, the word passenger $(s)$ in the context of a conveyance (ship, train, car, etc.) tends to implicate the 'conveyee' sense, as in (5), and even more strongly when used with the definite article. 'Passing traveller' increasingly needs contextual support. 
The $O E D$ as updated in 2005 has the following note against sense 4 of passenger:

N.E.D. (1904) notes 'now always with the implication of a public conveyance entered by fare or contract'. After motor vehicles, other than buses and coaches, became widespread this implication ceased to be felt.

One could speculate that extralinguistic factors - the enormous growth first of public (paidfor) transport and later also of private cars - might have strengthened the 'conveyee' sense. Can its dominance be linked to the loss of 'passing traveller (on foot)'? - a sense whose obsolescence by 1919 is suggested by the more explicit compound foot-passenger in (2)b. Perhaps potential ambiguity hastened the loss. Compare how the 'homosexual' sense of gay has made earlier senses almost unusable.

\subsection{Hidden ambiguity}

Ambiguity need not involve senses known to both SP/W and AD/R - a choice easily resolved if noticed. My definition of ambiguity encompasses the situation where $\mathrm{AD} / \mathrm{R}$ encounters an unfamiliar term and in effect makes a guess as to the meaning. AD/R's approximation to the original sense may later enter more general usage. Strictly speaking there is no ambiguity within the individual grammars of either SP/W or AD/R, since their patterns of usage barely overlap: ambiguity here is essentially a contact phenomenon, at least at first.

One obvious context is when a term from a technical jargon is recruited for more general use. Thus parameter is a term with exact meanings in various fields. Its sense in mathematics, illustrated in (6) below, is probably too subtle for most non-mathematicians: 
A quantity which is fixed (as distinct from the ordinary variables) in a

particular case considered, but which may vary in different cases $(O E D$, s.v.,

In more general discourse parameter has widened to '[a]ny distinguishing or defining characteristic or feature, esp. one that may be measured or quantified; an element or aspect of something', see (7), and for many speakers it has become merely a high-flown alternative to boundary or limit, as in (8) (both developments recorded in OED s.v., 8), the latter no doubt with some contamination from perimeter.

(6) This technique determines a new solution with one extra parameter $\alpha$. (BNC, B2K 727)

(7) It is their responsibility to decide what new equipments [sic] are needed, and to specify their performance and other critical parameters. (BNC, ABA 205)

(8) This sense of collaborative work [in a drama lesson] — within agreed parameters — is a key to good control and good drama. (BNC, HYA 944)

Vagueness may play a part in the spread of the innovation in examples which blur the distinction between a technical and a more general sense:

(9) The precise scale you can't quantify, but I can give you the parameters. (BNC, A44 371)

Other technical terms which have entered general usage with rather different meanings include at fault (originally of hounds which have lost the scent), crisis (moment when illness turns either towards recovery or death), quantum leap (the smallest possible change in energy level of an electron), and psychological terms like schizophrenic. 


\subsection{Pragmatic vagueness}

The closely related seventeenth-century Latin borrowings discriminate $\mathrm{v}$. and discrimination n. exemplify the development of new senses in interaction between pragmatics and semantics. They have by and large kept in step with each other through later semantic changes, which I label as stages A-D in Table 2 below. The next two columns of the table have a synopsis of the relevant senses in the respective $O E D$ entries, together with the date range over which each numbered sense is recorded. (Only sense 3 of the noun is marked as obsolete.) The last column notes whether there is an element of evaluation in the connotation.

\begin{tabular}{|c|c|c|c|}
\hline stage & discriminate $\mathrm{v}$. & discrimination $\mathbf{n}$. & evaluation \\
\hline A & $\begin{array}{l}\text { 2a. tr. 'distinguish } \mathrm{X} \text { (from Y)' } \\
\text { 1615- }\end{array}$ & $\begin{array}{l}\text { 1a. 'action of noting/making a } \\
\text { distinction (of X)' } 1621 \text { - }\end{array}$ & neutral \\
\hline A & $\begin{array}{l}\text { 2b. intr. 'distinguish (among } \\
\text { Xs; between } \mathrm{X} \text { and Y)' 1645- }\end{array}$ & $\begin{array}{l}\text { 1a. 'action of noting/making a } \\
\text { distinction (between } \mathrm{X} \text { and } \mathrm{Y} \text { )' } \\
\text { 1621- }\end{array}$ & neutral \\
\hline $\mathrm{A}^{\prime}$ & & $\begin{array}{l}\text { 3. 'fact/condition of being } \\
\text { differentiated' 1666-1867 }\end{array}$ & neutral \\
\hline $\mathrm{B}$ & & $\begin{array}{l}\text { 4. 'power/faculty of making exact } \\
\text { distinctions,; discernment' 1764- }\end{array}$ & $\begin{array}{l}\text { usually } \\
\text { positive }\end{array}$ \\
\hline $\mathrm{C}$ & $\begin{array}{l}\text { 3. econ., orig. U.S., intr. } \\
\text { '(against X), treat X (less) } \\
\text { favourably' 1786- }\end{array}$ & $\begin{array}{l}\text { 5. econ., orig. U.S. } \\
\text { '(un)favourable treatment' 1789- }\end{array}$ & neutral \\
\hline $\mathrm{D}$ & $\begin{array}{l}\text { 4. intr. '(against X), treat } \\
\text { unjustly' } 1857 \text { - }\end{array}$ & $\begin{array}{l}\text { 6. orig. U.S. 'unjust/prejudicial } \\
\text { treatment (against X)' 1819- }\end{array}$ & negative \\
\hline
\end{tabular}

Table 2: Some senses of discriminate/ion 
Some examples follow:

(10) an instance of the judgment of the ancient Sculptors in their nice discrimination of character. (1821-2, CLMET3.0) [stage A]

(11) Man would cease to be Man: on the one side he would lose his discrimination from God, and on the other from Nature. $(1867, O E D)$ [stage A']

(12) and ridiculing the public for their want of taste and discrimination in not admiring it (1838, CLMET3.0 [stage B]

(13) They do not discriminate against ships belonging to the other states $(1786, O E D)$ [stage C]

(14) a. More American women than ever before are filing charges that they're being discriminated against in employment. (1970, COHA) [stage D]

b. The discrimination of Arab-Americans since 9/11 has been vastly overlooked in society. (2005, COCA) [stage D, usage not yet in $O E D$ ]

The earliest stage for both verb and noun, A, illustrated in (10), carries no value judgement, nor the stage $\mathrm{A}^{\prime}$ of (11), which is merely a statal result use of discrimination - an easy kind of sense extension for action nouns, found also in commitment, extension, finding and many others.

In the eighteenth century the focus with the noun switches to the discriminator, stage B: discrimination regarded as a human faculty. This is a metonymy, or arguably an inference/implicature: the act or fact of discrimination implies the existence of a human mind endowed with the ability to make fine distinctions. Possession of that ability need not evoke a subjective evaluation, but one can easily arise through inference/implicature, in principle 
either positive (e.g. the faculty of a good judge) or negative (e.g. of a fusspot). Evidently it was positive connotations that stuck, perhaps through contextual association and repeated collocation with particular items, for example premodifiers like nice or coordination with taste or delicacy; cf. (12).

A separate semantic development, stage $\mathrm{C}$, focuses on the discriminatee, at first with a specialised use in trade and economics for the favouring or disfavouring of particular products or countries, as in (13). In this factual, technical usage there need be little or no subjective speaker evaluation - the sense is vague in that respect. However, an extension to human discriminatees in the nineteenth century facilitates the addition to both verb and noun of an inference/implicature 'unjust' or 'unjustified', a negative subjective evaluation, perhaps because (economic) discrimination against is much commoner than discrimination in favour of, both in practice (imposition of tariffs, or import bans, for example) and in language use. The addition of an 'unjust' element is favoured culturally or politically through changes in mainstream social attitudes, and linguistically through repeated premodification by racial or sex or by coordination with prejudice. If 'unjust' becomes part of the semantics, we have reached stage D, as in (14). Collocation with immediately following against is a convenient test to distinguish stages $\mathrm{C}$ and $\mathrm{D}$ from $\mathrm{A}, \mathrm{A}^{\prime}$ and $\mathrm{B}$. We can see the growth of discriminat* against in COHA (400 million words, 1810-2009):

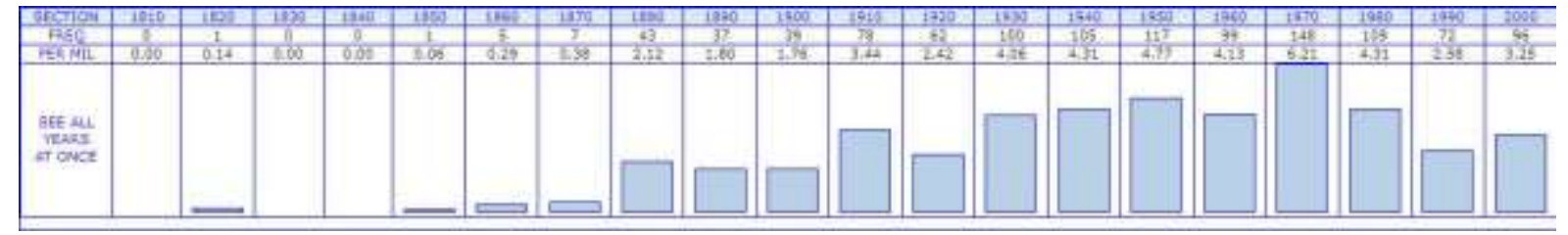

Figure 1: disciminat* against in COHA 
Figure 2 shows the growth in frequency of such premodifiers as race or $s e x{ }^{3}$ essentially from the 1920s onwards after sporadic attestations beginning in 1885 .

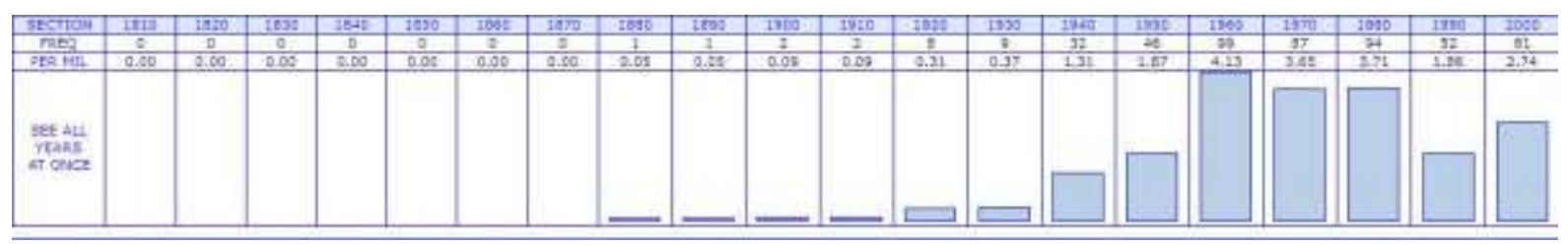

Figure 2: Selected premodifiers of discriminat* in СOHA

Although nearly all the senses mentioned here remain available, stage D is probably dominant in present-day use of both noun and verb, with older meanings needing more contextual support. Notice by contrast that the adjective discriminating seems to retain as its default a positive connotation similar to stage B. Other factors must determine the direction of semantic change and whether it takes place at all; pragmatic vagueness is merely a prerequisite.

A more recent example is sketchy, a denominal adjective used transparently from 1805 of writings or drawings in the sense 'giving only a sketch or outline' (my précis of $O E D$ s.v., 1 and 2). By 1878 a colloquial sense '[o]f a light, flimsy, unsubstantial or imperfect nature' (s.v., 3) is recorded, which I take to be a metaphorical extension: different domain, senses related by similarity. A further shift turns 'flimsy, imperfect' into 'unsafe, disreputable, dishonest', presumably when applied to such concrete or abstract referents as buildings or legality. Dubiousness and illegality are not yet recognised for sketchy by the $O E D$ but are current in the US (OxfordDictionaries.com: 'dishonest or disreputable'; Merriam-Webster:

\footnotetext{
${ }^{3}$ The search string age|race|racial|racially|racist|sex|sexual|sexist|ethnic discriminat* used for Figure 2 picks up racial discrimination and race discrimination, but also a few examples of racially discriminatory, etc.
} 
'likely to be bad or dangerous'; Urban Dictionary: 'gives off a bad feeling; unsafe'), even allowing a human referent:

(15) it pays to be suspicious of large, seemingly useless gifts from one's sworn enemy. And that includes your aunt's sketchy second husband. (2011 COCA, Caprice Crane, With a little luck: a novel)

These latest shifts in semantics are enabled by the source sense being pragmatically vague as to evaluation.

In the examples discussed it is mostly vagueness that promotes the change. Ambiguity can play a part in the aftermath but may be more centrally involved in language contact.

No attempt has been made to offer a complete typology of semantic change.

\section{Word class change}

Normal word class change is immediate and complete. There is no vagueness or ambiguity in derivations like funny adj. < fun n., hammer v. < hammer $\mathrm{n}$. , peddle v. < pedlar $\mathrm{n}$. One can, however, imagine a period of vagueness in developments of the bitter $\mathrm{n} .<$ bitter beer type, as mere ellipsis of a head noun after the adjective gives way to a new self-standing noun.

I have studied yet another kind of word class change, an incremental process which in the early stages requires an underdetermined word class - essentially an analytic vagueness. Such stepwise developments in English include determiner $<$ adjective, adjective $<$ verb, pronoun $<$ adverb, and adjective < noun. The old word class is not lost (cf. Section 2 on semantic change). We will look in detail at adjective < noun, particularly evident in recent decades in such words as 
(16) ace, amateur, apricot, bandaid, cardboard, champion, core, corker, cowboy, designer, dinosaur, draft, freak, fun, genius, key, killer, landmark, luxury, niche, pants, powerhouse, rubbish, surprise, toy, Velcro

\subsection{Stepwise adjective $<$ noun}

Noun and adjective are distinct word classes in English, but crucially they have some distributional properties in common. Both can occur as premodifier of a head noun, thus real adj. in (17) and inflation n. in (18):

(17) Gold is real money and paper is pretend money. (1974, OED)

(18) That's why inflation money is false purchasing power. (1946, WebCorp)

The word class membership of these two items is securely known from behaviour elsewhere. (More problematic is pretend in (17), which in other slots is more familiar as a verb.)

Nouns and adjectives also share the possibility of occurring as predicative complement, thus beautiful adj. and fakes $\mathrm{n}$. in (19), and fake adj. in (20). (The latter must be an adjective, since fake does not occur as a mass noun, and only mass nouns and plurals can form a grammatical NP without determiner.)

(19) ... a third of the pictures are beautiful, but I think two-thirds of the pictures are fakes. (BNC, EBX 1777)

(20) His gentleness was fake, ... . (BNC, BP7 1362)

The premodifier and sometimes the predicative complement contexts can leave the word class of their filler underdetermined if that word exists both as noun and adjective. Consider expert in these examples, uncontroversially an adjective in (21) and a noun in (22): 
(21) Naihe from Ka'u on the Big Island was so expert a surfer that his fellow chiefs grew jealous ... . (BNC, ASV 62)

(22) An expert's decision is usually final and binding. (BNC, J6Y 2079)

Note that the adjective goes back to Middle English, whereas the noun use can only be traced back to 1825 , probably by re-borrowing from French (OED s.v.): I am not citing this as an example of historical change, merely as a clear-cut case of synchronic homonymy for which PDE speakers need lexical entries both as noun and adjective. What then is the word class of expert in (23)?

(23) You could do it yourself or get expert help. (BNC, A0G 1488)

AD/R cannot know whether expert is noun or adjective here. This is vagueness, not ambiguity, since the choice makes no difference to interpretation and no difference to constituent structure. Psycholinguists might invoke the concept of 'good enough' processing here (Felser this volume).

I would argue further that the SP/W of (23) need not have decided between two lexical entries for expert, although such a claim would pose difficulties for some models of language production. In the same vein, it seems to me arbitrary for a linguist to privilege one classification or the other by assigning either Adj or $\mathrm{N}$ to expert in (23) (and concomitantly AP or NP to its projection). If a decision is demanded by a linguistic theory which takes unique word class to be universal and basic, maybe the theory should be questioned.

Be that as it may, the kind of analytic vagueness seen in (23) is crucial in the histories of words (unlike expert) that start out as nouns but which come to show adjectival behaviour as well. The premodifier and predicative slots are what we might call syntactic bridging contexts. When such a word appears there, AD/R may be prompted to regard it as an 
adjective even if SP/W only has a lexical entry as noun, especially with a referent that is semantically gradable. ${ }^{4}$ I consider some evidence of stepwise progression towards full adjective behaviour, with examples taken from the list of words in (16).

\subsubsection{Vague $\mathbf{N} \sim$ Adj contexts}

Frequent use of a noun as an attributive modifier of other nouns may suggest that it is in some way adjectival:

(24) ... he reeled through four savage rounds before he got the killer punch ... (1982, COHA)

And indeed the noun killer has developed a sense "[v]ery effective; excellent, "sensational", (OED s.v., 7b, 1979- ), with later examples than those in the $O E D$ showing other and better evidence of true adjectival status; see (31), (35) below.

Neutralisation in predicative complement position is possible when NP and AP take the same form, i.e. if the noun is non-count:

(25) Oh! it was fun! (1872, COHA)

At that date fun was most probably a noun, but after the 1960s, when for some speakers fun had developed full adjectival behaviour alongside its noun use, examples like (25) are syntactically underdetermined - at least for such speakers.

If the word in question is coordinated with a true adjective, as fun is with safe in (26), then $\mathrm{AD} / \mathrm{R}$ may well take it to be an adjective too:

(26) ... so that the hobby, which often proved fatal, would be safe as well as fun. (1966, TIME)

\footnotetext{
${ }^{4}$ On possible semantic gradability in nouns, see Gnutzmann (1975), Huddleston \& Pullum (2002: 532).
} 
However, coordination is not a knockdown test of category status, as in the right context, different phrasal categories can be successfully coordinated (Huddleston \& Pullum 2002: 1326-9):

(27) a. She was old and a snob. (BNC, CDY 1516)

b. $\quad .$. her father, who is now elderly and in poor health. (2011, COCA)

\subsubsection{Contexts weighted towards Adj}

Premodifiers are subject to constraints on their relative order: determiners generally precede adjectives (for a systematic exception see (21)), certain types of adjective typically precede others (a tall friendly old man vs. ?*a tall old friendly man, ?an old tall friendly man, etc.), and modifying adjectives typically precede modifying nouns (an expensive visitor experience vs. *a visitor expensive experience). This last claim gives us a test of adjective status, since if an attributive modifier like powerhouse occurs to the left of a clear adjective like new, it should be an adjective itself rather than an attributive noun:

(28) The powerhouse new bestseller from ELIZABETH GEORGE (1996 Bantam Press advertisement, The Guardian p. 1 (3 Feb.))

However, once again there are exceptions which suggest that the ordering 'rule' is merely a strong tendency, since there is no reason to think that emergency or deathbed are in any way adjectival:

(29) In the case of an emergency premature delivery ... . (2008, WebCorp)

(30) I just got a different feel from the movie/novel - that Padme's deathbed final words were to be understood as more than a mere guess. (2009, WebCorp)

Although N-Adj orderings for premodifiers are much less common than Adj-N, relative order cannot be a sufficient condition for distinguishing adjective from noun. 
Modification by very provides an indication of killer's adjective status in (31):

(31) WOOOOOOOW sexy mistress posing in very killer stainless steel custom made 9inch high heels! (2013, via WebCorp)

Inconveniently, the same sorts of modifier - so, very, too, etc. - go with proper names (usually taken to be NPs) when the person or place has well-known identifying characteristics, as in (32), though not with common nouns. This weakens the test without vitiating it.

(32) It's very silly, it's very odd, it's very Woody Allen. Love it. (2008, http://www.sofacinema.co.uk/visitor/product/2584-Everything-You-Always-WantedTo-Know-About-Sex-But-Were-Afraid-To-Ask.html)

\subsubsection{Clearly adjectival contexts}

Comparison is a property of prototypical adjectives that nouns lack. When a form in transition from noun to adjective develops a comparative or superlative, it has reached its destination. The syntactic comparison of key in (33) is arguably a variant of the use of intensifiers discussed just above, while morphological comparison, as in (34), is even more telling:

(33) So therefore that was more key to you than $[\ldots]$ ? That was more important to you? (1995, COCA)

(34) Mirror, mirror on the wall, who's the keyest of them all... (2001 http://www.purplehunt.com/usedclues.htm (31 Jan))

Some examples raise questions about linguistic playfulness vs. genuine grammaticality, but the more pertinent point is that during a transition, some speakers will be more advanced, others more conservative; see Section 3.2 below. 
Given that the distributions of AP and NP overlap in the role of pre-head modification, Huddleston uses the criterion of post-head modification to help distinguish APs (see e.g. Huddleston \& Pullum 2002: 528-9, 552-553, 559-561, Matthews 2014: 10-13).

Postmodification is possible after indefinite pronouns and sometimes when the adjective is coordinated or has its own dependents:

(35) Each track has something killer on offer (2013, via WebCorp)

(36) A really lovely tea towel for your husband, wife, girlfriend, boyfriend, best friend, or anyone ace in your world! (2015, via WebCorp)

(37) Adler believes in filling your surroundings with all things fun and [j]oyful, ... (2005, COCA)

Certain derivational processes typically build on adjectival rather than nominal stems, for example addition of $-l y$ to form an adverb, and hence may serve as a test: ${ }^{5}$

(38) The concept of his art is inherently hard to put into words. But most commonly (and amateurly put), Turrell's Skyspaces can be described as ... (2013, via WebCorp)

(39) Trying to explain the ferry system very draftly (2015, via WebCorp)

\subsection{Partial word class change}

If such words as those listed in (16) simply developed a new adjective use by conversion, and if word classes were Aristotelian categories, then all the adjectival properties mentioned in Section 3.1 should arrive simultaneously. But they don't: acquisition of adjective behaviour is generally step-wise rather than all at once. We see this both in corpus data and in informant testing, with speakers considering some but not all adjectival properties acceptable. In

\footnotetext{
${ }^{5} O E D$ cites as solitary exception the denominal adverb partly (s.v. -ly suffix ${ }^{2}$ ).
} 
Denison (2010a: 110-11) I cited some examples of the word rubbish that were indeterminately noun or adjective plus others that should have been impossible for a noun. What was striking was the acceptability judgements the data evoked in a group of students. The more obviously adjectival contexts (comparative and superlative forms, modification by very) scored poorly, averaging in the range $1.95-2.55$ out of a maximum 5 , as against 4.70 4.75 for the vague ones. This was not unexpected for a recent innovation. Yet the use of rubbish to postmodify an indefinite pronoun scored 4.6 - in other words, was found to be almost wholly acceptable. This remains to be confirmed by a proper psycholinguistic study, but I have little doubt that the result is robust and is largely independent of prescriptivist influence.

For another, similar case, the following attested examples support the categorisation of fun as adjective, but with differing acceptability:

(40) Doing something fun like redecorating your room..is really interesting biz for a teen who loves being busy. (1951, OED s.v. teen n.2)

(41) And they are so fun to eat! (1979, COHA)

(42) Walking and looking is boring. Touching is funner. (1990, COCA)

Most speakers I have consulted accept the postmodification of (40) but reject the comparative of (42), while the acceptability of so fun in (41) (as opposed to such fun) is intermediate and more or less inversely correlated with age. Denison (2013) argues that differential acceptability of new patterns and the stepwise nature of change point to grammatical variation within a population, and that corpus techniques which rely on pooled data can only give limited insight; furthermore, a writer's date of birth may be as pertinent as date of publication. Informant testing with psycholinguistic techniques would be a better way of getting a snapshot of change in progress and teasing out the diachronic significance of word 
class vagueness. But of course the view of word classes espoused here has synchronic consequences for linguistic theory too.

\section{$4 \quad$ Prefabs and chunking}

I use 'prefab' as a pretheoretical cover-term for a ready-made multiword unit. Recall the apparently anomalous word order of emergency premature delivery in (29) and deathbed final words in (30). The predictable orders might have been premature emergency delivery and final deathbed words, respectively (and both of these sequences are attested elsewhere), but syntax can apparently be overridden by a conflicting tendency to keep premature delivery and final words - incipiently lexicalising - as uninterrupted prefabs. Frequently recurring strings are liable to coalesce into prefabs.

The term 'chunking' is sometimes adopted from psychology (see for instance Beckner \& Bybee 2009: 30-31 and references there, Ellis this volume). Does a potential prefab behave as a single chunk, or can it be seen as a string of separate words, some of which have individual morphosyntax or recognisable semantics? Or indeed as both?

We take the view that it is altogether common even for an individual speaker to have nondiscrete syntactic representations for the same word sequence. [...] Specifically, syntactic constituents are subject to ongoing influence from general, abstract patterns in language, in addition to more localized, itemspecific usage patterns. The foregoing perspective makes it possible that the same word sequence may be characterized by multiple constituent structures and that these structures have gradient strengths rather than discrete boundaries. Our position in this article is thus that constituency may change in 
a gradual fashion via usage, rather than via acquisition, and that structural reanalysis need not be abrupt. (Beckner \& Bybee 2009: 28-9)

Adoption of this position implies the presence of structural ambiguity or vagueness.

The formation of units from a recurrent sequence of free-standing elements plays an important part in both grammaticalisation and lexicalisation, whether the endpoint is a multiword unit or a word or morpheme. Historical change often involves a gradual shift from the component analysis to the prefab analysis (Bybee \& Moder this volume). Synchronically too there are many cases where language users can switch between the two.

A classic example is the analysis of strings like in front of, on behalf of. Quirk et al. (1985: 669-73) and Hoffmann (2005) among others compare the merits of a prefab analysis as complex preposition with a component analysis where each word is assigned an individual word class. Beckner \& Bybee (2009) trace the semantic development of in spite of from OED data, showing how it diverges from that of the noun spite ('grudge, rancorous malice', etc.) and moves towards a concessive sense, with some examples showing 'ambiguity' (in my terms, more like vagueness) between the sense of the noun in isolation and the new counterexpectation sense of the prefab:

(43) In spite of this aimlessness the wealth and empire of England are constantly increasing. $(1859, O E D)$

They argue that it is valid and indeed necessary to adduce semantics as well as syntax in working out constituency.

Formalist and structuralist approaches, by contrast, usually insist on the linguist identifying the unique/correct/best analysis of a given sentence after weighing up the (non-semantic) 
evidence. The consequence is likely to be rejection of a prefab analysis if there is any sign whatsoever of autonomy in one or more of the component words, as for example in Huddleston \& Pullum (2002: 618-23), where consideration is given only to structural analyses in which the putative complex preposition is not a constituent; any possible unit status for the whole string belongs to semantics or to the lexicon. Historical, psychological and corpus linguistic evidence suggests that such rigidity misses an essential truth about variation and change.

Below I identify ambiguity and vagueness in two different kinds of prefab.

\subsection{Sort of/kind of/type of}

Phrases consisting of the so-called SKT nouns with of are highly frequent strings: sort/kind/type + of occurs 46,064 times in the BNC at a rate of 468.54 per million words, equivalent to being among the 200 most frequent word tokens in the corpus.

The broad outlines of the history of SKT were sketched in Denison (2002), though subsequent work has refined certain parts of the picture and more data are available, while the fullest published examination of their syntax in PDE - within the NP at least - has been by Keizer (2007), and of their diachronic semantics by Brems \& Davidse (2010). ${ }^{6}$ Among the uses which have been identified are:

(44) ... the Canadians had one sort of sovereign, and the British had another sort. (BNC, A69 1471) [referential/binominal]

(45) There was a kind of inevitability about the whole proposal which appalled Alexei. (BNC, G17 1172) [qualifying]

\footnotetext{
${ }^{6}$ Other work on SKT nouns includes Aijmer (1984), Meyerhoff (1992), Tabor (1993), Kay (1997), De Smedt (2005), De Smedt, Gries \& David (2007), Davidse (2009), Denison (2010b).
} 
(46) It kind of built his confidence with each successive flask. (BNC, A14 937) [adverbial]

(47) ... but she should keep those sort of remarks to herself. (BNC, CDY 1447) [postdeterminer/complex determiner]

(48) They are used to all sorts of emergencies, ... (BNC A2X 404) [quantifying]

(49) It was a grim sort of place, ... (BNC, A2J 4) [descriptive modifier]

Now, even Huddleston \& Pullum (2002: 621) recognise reanalysis in the adverbial (46) type, where of can hardly be called a preposition any more. As shown in Denison (2002), modified by Brems \& Davidse (2010), it is possible to reconstruct the developmental paths of the various idiomatic uses of sort of and kind of, and in each case there are intermediate examples which are either vague or ambiguous. Here I give just three, the last involving not just the prefab kind of but also the newer prefab kind of thing, which has been developing into a discourse particle:

(50) 'Don't worry, a bit of body-popping won't kill me.'

'What on earth is body-popping?'

'It's a sort of dancing. Why, what did you think it was?' (BNC, A0F 2702-5)

(51) I Answered, That Religion being a design to recover and save Mankind, was to be so opened as to awaken and work upon all sorts of people, and generally men of a simplicity of Mind, were those that were the fittest Objects. (PPCEME, Burnet 1680)

(52) It created this mushroom kind of thing that people stared at. (BNC, AB5 1270) In (50), sort can be head in the binominal construction ('one variety of dancing'), or dancing is head in the qualifying construction ('something roughly answering to dancing'). The semantic difference is slight but identifiable, so this is probably best viewed as ambiguity. Example (51) is taken from Brems \& Davidse (2010: 188), where it is suggested that a binominal use of sort quantified by all offers an invited inference of a great number, which 
can then be semanticised in later examples as the quantifying meaning of all sorts of. In (52), either mushroom is a modifier and kind of thing is nominal, or mushroom closes the NP, in which case kind of thing becomes an adverbial hedge. Structurally this must be a case of ambiguity, though pragmatically it makes little difference.

\subsection{Piece of work}

A famous line in Hamlet is probably indirectly responsible for a modern application of the phrase piece of work to human referents:

(53) What a piece of worke is a man! (1623, Hamlet First Folio II.ii)

The definition the $O E D$ gives (s.v. piece n. $\mathrm{P} 4$, c.) is

colloq. (freq. derogatory). A person, esp. one notable for having a strong

(usually unpleasant) character. Usu. with modifying word; cf. NASTY adj. 2c.

In the BNC, 12 out of 190 examples of the string piece of work have a human referent. One is the Shakespearean quotation of (53) in modern spelling, one is (54), and the remaining 10 are all preceded by the adjective nasty, as in (55):

(54) 'You're some piece of work, Mrs Sutherland, you know that?' (BNC, FPF 1142)

(55) a. You'd best steer clear of him, Manderley, he's a nasty piece of work. (BNC, HJC 1764)

b. He was also a member of the Mafia, and he was up to his eyeballs in drugs. Altogether a very nasty piece of work. (BNC, GV6 3045)

(56) It was a nasty piece of work, done with thoroughly malicious intent. (BNC, K4W 477) (Example (56) is the only time nasty piece of work is used of a non-human referent.) 
Clearly, then, we have a prefab, somewhat lexically and semantically restricted, which plays its part in production and reception. However, the precise extent of the prefab is vague. It might, for example, be any of

(57) a. piece of work

b. a piece of work

c. $\quad a$ ([optional intensifier]) [pejorative adjective] piece of work

d. $\quad a(\ldots)$ nasty piece of work

Any decision is going to be somewhat arbitrary. Such vagueness as to the boundaries and the fixedness of an idiom, though no hindrance to communication, is problematic for purely algorithmic theories of language use where a specific lexical item has to be mapped against an interpretive component.

\subsection{The process of chunking}

What we see here is prefabs of different degrees of schematicity, whose parts may be inflected or interrupted (Bybee 2013: 54) - and interrupting elements are freely chosen in some cases but in others tend to come from a restricted set (as in Section 4.2). This supports a usage-based model of language involving emergent grammar, where both prefab and wordby-word analyses play a part, but to different degrees, and the proportions change over time. That, however, is a statistical overview. What of the individual utterance? As soon as we turn our conscious attention to the wording, we are pushed towards recognising syntactic ambiguity, as however potentially present the two (or more) analyses may be, it is hard to conceive of them as simultaneously active (cf. non-linguistic perceptual ambiguities like Rubin's vase or the Boring figure). What actually happens in the routine, unthinking speech situation is a question for psycholinguists to resolve. Hilpert (this volume: Section 3.6) notes that 'the linguistic competence of speakers must include probabilistic knowledge of 
variation'. Speakers are certainly (unconsciously) aware of alternative analyses of a potential prefab, and a speculative extension of Hilpert's observation would suggest that the relative strengths of the variant analyses of a given string might also form part of speakers' competence.

Structural ambiguity is not incompatible with semantic or pragmatic vagueness. Such vagueness can contribute to the ill-definedness of chunking in a given utterance and promote the gradual formation of prefabs.

\section{Structural change}

While chunking is the accretion of two or more separate words or morphemes into a larger whole, schematically A B > [A B] or AB, with concomitant semantic and phonological changes, the topic of this section is the related one of reassignment of constituency, A [B C]

$>$ [A B] C, often called rebracketing or reanalysis or, more recently, neoanalysis (Traugott \& Trousdale 2013). Here there is a dissociation of $B$ and C. Chunking is involved if $[A B]$ is a recurrent string, though purely syntactic reorganisation is possible too. Reanalysis has been taken to be a central mechanism of syntactic change (Langacker 1977: 57, Harris \& Campbell 1995: 61), though Haspelmath (1998) - in a discussion of grammaticalisation - relegates it to a minor role, and Traugott \& Trousdale (2013) suggest that it typically applies to 'microsteps' rather than bringing about wholesale reorganisation.

The consensus among proponents of reanalysis is that structural ambiguity is a necessary precondition. Paradoxically, however, reanalysis may go ahead even if only a few subtypes of the pattern in question are actually ambiguous (Timberlake 1977: 148-50). For example, a change of grammatical relations such as indirect object to subject may apparently need the 
NP in a particular surface pattern to have no case marking, or at most a neutralised dative-ornominative inflection, yet in practice it may be that only a minority of NPs in that pattern have an appropriate (lack of) case marking; such a subset of contexts is called the 'basis of reanalysis' by Harris \& Campbell (1995: 72).

An alternative to structural change is promoted by Whitman (2001), Garrett (2012), and Whitman (2012), with the claim that most or all alleged examples of reanalysis involve processes other than reassignment of constituent structure: grammaticalisation, analogy, the relabelling of nodes; see also Fischer (2007), De Smet (2009), Kiparsky (2014). Rather than ambiguity of structure, it is vagueness that allows change to take place.

To begin with, however, I couch both my examples in terms of reanalysis.

\subsection{Prepositional passive by reanalysis}

The prepositional passive begins to appear around 1200 (Denison 1985, 1993: 124-7, 14043). Fischer \& van der Wurff (2006: 196-7) explain its advent as follows. A general change in word order culminating in Middle English turned English from a V-2/V-final language into what is sometimes called a V-3 or SVO language, after which a PP collocated with an intransitive verb would almost always follow the verb directly, with verb and preposition adjacent. $^{7}$ This routine adjacency enabled a reanalysis to take place:

(58) $\mathrm{V}[$ PP P NP] $>[\mathrm{v}$ V + P $] \mathrm{NP}$

Thus, for example, probably through frequent euphemistic use, lie by 'lie beside' can develop the meaning 'have sexual intercourse with', (59). The semantic change and concomitant

\footnotetext{
${ }^{7}$ Mentioned also as a factor in Denison (1993: 143). Notice, though, that some early prepositional passives are verb-final, albeit usually in verse.
} 
chunking of verb and preposition allows reanalysis (58) to go ahead, weakening or destroying the unity of the PP. Now the string lie by behaves as if the following NP is complement not of the preposition alone but of the new transitive composite verb, and so a passive can be formed, (60).

(59) Vulcanus..foond thee lyggyng by his wyf allas. (c1385, MED)

Vulcan ... found you 'lying by' his wife alas

(60) Pis maiden..feled al so bi her pi Pat sche was yleyen bi. (c1330(?a1300), MED) ${ }^{8}$ this maiden ... felt also by her thigh that she had-been 'lain by'

A similar process explains the early advent of passives of such prepositional verbs as fare with 'deal with, treat', send after 'summon', speak of 'mention', and so on.

I have made a case for the new construction to have spread at first by lexical diffusion among closely related verb-preposition combinations (Denison 1993: 141). More generally, Fischer \& van der Wurff (2006: 197) observe that the semantics of prepositional verb combinations has to allow an 'object interpretation' of the complement NP. Typical semantic roles for such NPs are Stimulus or Cause with experiential verbs and Patient or Goal with others (Denison 1993: 140-1). Dreschler (2015: 120-25) advocates syntactic reanalysis but makes a case for its acceptability passing almost unnoticed via minimal alteration of several existing structures.

\subsection{Prepositional > phrasal verb by reanalysis}

In one context the polysemous prepositional verb run over undergoes an interesting semantic and syntactic change in late Modern English. There are numerous examples in the Old Bailey Corpus (14 million words, 1720-1913) where the literal sense of intransitive run involving

\footnotetext{
${ }^{8}$ Dreschler (2015: 111-12) is troubled by the fact that (60) is a verse example.
} 
rapid movement of a person or (part of) a vehicle collocates with an over-phrase to indicate path, (61), and for quite a few of these the context is a (potential) collision, (62):

(61) ... we pursue'd him over the Downs, and towards a Wooden Bridge at the Bottom of the Downs ... . He ran over the Bridge (The Old Bailey Corpus 1720-1913 (version 1.0, 2013-06-04), 1739, t17390718-10)

(62) a. it was bent, and look'd as if a Coach-wheel had ran over it. (OBC, 1732, t17320114-38)

b. I saw a Hansom cab standing at No. 21; I saw it go past our door; the prisoner was driving it - it was going very fast - it knocked the men down and ran over them (OBC, 1878, t-18780311-341)

Now consider a collision example like (62) made passive - also frequent:

(63) the man was run over on the legs [...] it was through the furious driving - he was knocked down by either the bar or the van, I could not take my oath which (OBC, $1861, \mathrm{t}-18610408-325)$

(64) a. a young woman with a child in her arms endeavour'd to stop the horses; I called to her to let them go, as I saw she would be run over else (OBC, 1770, t17700711-39)

b. the prisoner came up and told me I was not to go too fast, for if I did I should get run over - she told me to wait till all the carriages and horses were gone by $(\mathrm{OBC}$, $1849, \mathrm{t}-18490226-699)$

There is a potential structural and semantic ambiguity in (64) (but not (63)): either over is a preposition referring to the trajectory of the moving vehicle across and above an obstacle, or it is a resultative adverbial particle describing the trajectory of the victim out of upright position, part of a transitive phrasal verb run over 'injure with a vehicle', like knock down. In general, Patient or Goal is a typical semantic role for the subject of a prepositional passive 
(Section 5.1 above), and that association would encourage the innovative reading of (64), where the Patient role is even more marked. Note that another potential source of ambiguity doesn't seem to be much in evidence in the period of reanalysis, namely active VPs with a non-pronominal NP: active run over NP could in principle be ambiguous between prepositional and phrasal verb, but I have found no convincing examples in $\mathrm{OBC}$, only in later corpora.

After reanalysis of the passive to the phrasal verb structure, new patterns become possible:

(65) a. She $[\ldots]$ got on her bike and roared off. My father tried to stop her by standing in her way, so she ran him over and broke his leg quite badly (BNC, HWC 2340) b. Someone's going to run a little child over soon because the lollipop lady is busy asking drivers to move on. (BNC, K55 9072)

Since over follows the object NP in (65), it must be an adverbial particle rather than a preposition.

The period of transition seems to be largely in the second half of the twentieth century. I could not find any clear examples of active run over in the required sense as a phrasal verb in COHA until 1949, 1955 and later. ${ }^{9}$ Interestingly, the linguistic change is observed around then by Wood (1955-6: 22, and see also Parker 1976: 451-2). However, the $O E D$ has managed to trace the pattern as far back as 1860 (s.v. run v. PV1, 1). A similar ambivalence between prepositional and phrasal verb analysis, but often with unclear semantic difference or directionality of change, is seen in verbs like pass, read in combination with path particles like by, over, through and (less often) about, round.

\footnotetext{
${ }^{9}$ Search strings in COHA were "[run] me|you|him|her|us|them over" and "[run] a|the *.[N*] over".
} 


\subsection{Reformulation without reanalysis}

Is reanalysis important in language change? Indeed, is it real? To some extent the questions are terminological, but only to some extent. If most reanalysis scenarios can be repackaged convincingly as examples, say, of analogy, there are real consequences. Directionality and context of change may be better explained. SP/W becomes as important as AD/R in such changes - or more important, even. And change is not so limited to the life stage of language acquisition; see here Lieven's (this volume) argument against child errors as a source of change and also López Couso (this volume).

Consider the examples discussed above. For the prepositional passive, two crucial ingredients of the new structure are already in place before it appears, namely passive verb participles and stranded prepositions (the latter in relative and infinitive clauses, for instance). Furthermore, some of the actual lexical verbs that appear in the prepositional passive early on are (more) often used transitively and therefore already have conventional passives: do, let, send, set, tell, perhaps tend. Therefore the new kind of passive could have been formed analogically rather than - or as well as - by reanalysis in the active. Its structure is vague, related as it is at one and the same time to its equivalent in the active voice, to other kinds of stranding pattern, and to other kinds of passive; cf. here the notion of 'serial relationship' (Quirk 1965), and now also Dreschler's (2015) rather different take on multiple resemblances to existing structures.

Turning to the replacement of the prepositional verb run over by a phrasal verb, the new structure is well established in the language for other phrasal verbs (including many with over) long before the change in question. In the context of vehicle collisions with pedestrians, it is not clear how much of a semantic difference there is between the two passive structures, 
so that there is at least a case to be made for semantic vagueness rather than ambiguity in the construction as a whole (though not for the semantics and syntax of over).

It looks as if the apparently reanalysed structures, or something closely similar, had a prior existence with other exponents or in other contexts. Such extension of an existing structure to new material shows innovation 'sneaking in' where least salient. In my case studies there is a clear semantic or pragmatic component. If this is a precursor of the structural change, then the structural change (or changes, if analysed in terms of micro-steps) would seem to arise from vagueness rather than ambiguity.

\section{Closing remarks}

I have presented a varied sample of historical phenomena that involve the notions of ambiguity and/or vagueness. A fuller survey could bring in examples from phonology, language (and dialect) contact, grammaticalisation and discourse, to name some obvious gaps, as well as finding space for a more nuanced discussion of grammaticality and grammaticality judgements. Even within the limitations of the sample, however, we see how often it is necessary to consider related changes in different domains - syntax, semantics, pragmatics, chunking, etc. Whether this is an argument for a cascade of effects across selfcontained linguistic modules or an argument against modularity is beyond the scope of this chapter.

Change often has a beginning in vague contexts where the old analysis remains viable. This is consonant with the general proposition that less salient contexts lead change; see here Traugott (this volume: Section 5.3), particularly in relation to morphosyntactic change, and De Smet (2012: 605) (“language change is 'sneaky"”). If Ellis (this volume: Sections 1.3.1 
and 2), by contrast, associates change with high salience, that may indicate that the kinds of change discussed here are not, or not exclusively, associated with early L1 acquisition.

As for ambiguity vs. vagueness, vagueness is typically an enabler of change 'from below' (in the sense of unconscious change), though other factors determine whether and how the change proceeds. Ambiguity seems to be more peripheral and is often the result of change though it may then prompt further, prophylactic change from above. Change via micro-steps would fit well with a variation-space that is closer to vagueness than to ambiguity. Ambiguity and vagueness represent two extremes of incomplete knowledge for language users, but linguists should engage with them as 'known unknowns'.

\section{Abbreviations for sources of examples}

BNC $=$ The British National Corpus, version 3 (BNC XML Edition). 2007. Oxford University Computing Services on behalf of the BNC Consortium.

CLMET3.0 = De Smet, Hendrik , Hans-Jürgen Diller \& Jukka Tyrkkö. [date?]. The Corpus of Late Modern English Texts, version 3.0, https://perswww.kuleuven.be/ u0044428/

COCA = Davies, Mark. 2008- . The Corpus of Contemporary American English: 450 million words, 1990-present. Available online at http://corpus.byu.edu/coca/

COHA = Davies, Mark. 2010- . The Corpus of Historical American English: 400 million words, 1810-2009. Available online at http://corpus.byu.edu/coha/ IMEPC $=$ Innsbruck Middle English Prose Corpus (Sampler)

118C Prose $=$ Denison, David, with the assistance of Linda van Bergen \& Joana Soliva. 2003. A Corpus of late 18c Prose (The English language of the north-west in the late Modern English period), http://personalpages.manchester.ac.uk/staff/david.denison/late18c 
$M E D=2001$. Electronic Middle English dictionary. Ann Arbor: University of Michigan Press, http://quod.lib.umich.edu/m/med/

OBC $=$ Huber, Magnus, Magnus Nissel, Patrick Maiwald \& Bianca Widlitzki. 2012. The Old Bailey Corpus. Spoken English in the 18th and 19th centuries. www.unigiessen.de/oldbaileycorpus [searches made on offline 2010 version, examples checked online]

OED = Oxford English Dictionary (OED Online). 2000- . Oxford University Press, http://www.oed.com/

PPCMBE $=$ Kroch, Anthony, Beatrice Santorini \& Ariel Diertani. 2010. Penn Parsed Corpus of Modern British English, http://www.ling.upenn.edu/hist-corpora/PPCMBERELEASE-1/index.html

TIME = Davies, Mark. 2007- . TIME Magazine Corpus: 100 million words, 1920s-2000s. Available online at http://corpus.byu.edu/time/

WebCorp = 1999-2015. WebCorp Live, http://www.webcorp.org.uk/live/

WebCorp LSE = 1999-2013. WebCorp Linguist's Search Engine, http://wse1.webcorp.org.uk/home/

\section{References}

Aijmer, Karin. 1984. 'Sort of' and 'kind of' in English conversation. Studia Linguistica 38, 118-28.

Beckner, Clay \& Joan Bybee. 2009. A usage-based account of constituency and reanalysis. Language Learning 59.4, 27-46.

Brems, Lieselotte \& Kristin Davidse. 2010. The grammaticalisation of nominal type noun constructions with kind/sort of: Chronology and paths of change. English Studies $91.2,180-202$. 
Bybee, Joan L. 2013. Usage-based theory and exemplar representations of constructions In Thomas Hoffmann \& Graeme Trousdale (eds.), The Oxford handbook of construction grammar (Oxford Handbooks in Linguistics), 49-69. Oxford: Oxford University Press.

Bybee, Joan \& Carol Lynn Moder. in prep.,2015. Chunking and changes in compositionality in context. In Marianne Hundt, Sandra Mollin \& Simone Pfenninger (eds.), The changing English language: Psycholinguistic perspectives (Studies in English Language). Cambridge: Cambridge University Press.

Davidse, Kristin. 2009. Complete and sort of: From identifying to intensifying? Transactions of the Philological Society 107.3, 262-92.

De Smedt, Liesbeth. 2005. Functions of the T-nouns kind, sort and type: A comprehensive, data-based description. MA dissertation, University of Leuven.

De Smedt, Liesbeth, Lieselotte Brems \& Kristin Davidse. 2007. NP-internal functions and extended uses of the 'type' nouns kind, sort, and type: Towards a comprehensive, corpus-based description. In Roberta Facchinetti (ed.), Corpus linguistics 25 years on (Language and Computers - Studies in Practical Linguistics 62), 227-57. Amsterdam and New York: Rodopi.

De Smet, Hendrik. 2009. Analysing reanalysis. Lingua 119.11, 1728-55.

De Smet, Hendrik. 2012. The course of actualization. Language 88.3, 601-33.

Denison, David. 1985. Why Old English had no prepositional passive. English Studies 66, 189-204.

Denison, David. 1993. English historical syntax: Verbal constructions (Longman Linguistics Library). London and New York: Longman.

Denison, David. 2002. History of the sort of construction family. Paper presented at ICCG2: Second International Conference on Construction Grammar, Helsinki. 
Denison, David. 2010a. Category change in English with and without structural change. In Elizabeth Closs Traugott \& Graeme Trousdale (eds.), Gradience, gradualness and grammaticalization (Typological Studies in Language 90), 105-28. Amsterdam and Philadelphia: John Benjamins.

Denison, David. 2010b. SKT-constructions: The relation between synchronic and diachronic analysis. Paper presented at SLE 43, Vilnius.

Denison, David. 2013. Parts of speech: Solid citizens or slippery customers? Journal of the British Academy 1, 151-85.

Diewald, Gabriele. 2002. A model for relevant types of contexts in grammaticalization. In Ilse Wischer \& Gabriele Diewald (eds.), New reflections on grammaticalization (Typological Studies in Language 49), 103-20. Amsterdam: John Benjamins.

Dreschler, Gea. 2015. Passives and the loss of verb second: A study of syntactic and information-structural factors (LOT dissertation series 402). Utrecht: LOT.

Ellis, Nick. in prep.,2015a. Chunking in language usage, learning, and change: I don't know. In Marianne Hundt, Sandra Mollin \& Simone Pfenninger (eds.), The changing English language: Psycholinguistic perspectives (Studies in English Language). Cambridge: Cambridge University Press.

Ellis, Nick. in prep.,2015b. Salience in language usage, learning, and change. In Marianne Hundt, Sandra Mollin \& Simone Pfenninger (eds.), The changing English language: Psycholinguistic perspectives (Studies in English Language). Cambridge: Cambridge University Press.

Evans, Nicholas \& David Wilkins. 2000. In the mind's ear: The semantic extensions of perception verbs in Australian languages. Language 76.3, 546-92.

Felser, Claudia. in prep.,2015. Syntactic ambiguity in real-time language processing and diachronic change. In Marianne Hundt, Sandra Mollin \& Simone Pfenninger (eds.), 
The changing English language: Psycholinguistic perspectives (Studies in English Language). Cambridge: Cambridge University Press.

Fischer, Olga. 2007. Morphosyntactic change: Functional and formal perspectives (Oxford Surveys in Syntax and Morphology 2). Oxford: Oxford University Press.

Fischer, Olga \& Wim van der Wurff. 2006. Syntax. In Richard M. Hogg \& David Denison (eds.), A history of the English language, 109-98. Cambridge: Cambridge University Press.

Garrett, Andrew. 2012. The historical syntax problem: Reanalysis and directionality. In Dianne Jonas, John Whitman \& Andrew Garrett (eds.), Grammatical change: Origins, nature, outcomes, 52-72. Oxford and New York: Oxford University Press. Gnutzmann, Claus. 1975. Some aspects of grading. English Studies 75, 421-33.

Gries, Stefan Th. \& Caroline David. 2007. This is kind of/sort of interesting: Variation in hedging in English. VARIENG e-Series 2 2, Towards multimedia in corpus studies. Helsinki: Research Unit for Variation, Contacts and Change in English (VARIENG). http://www.helsinki.fi/varieng/journal/volumes/02/gries_david/ < Accessed 23 Aug 2010>.

Hansen, Maj-Britt Mosegaard \& Richard Waltereit. 2006. GCI theory and language change. Acta Linguistica Hafniensia 38, 235-68.

Harris, Alice C. \& Lyle Campbell. 1995. Historical syntax in cross-linguistic perspective (Cambridge Studies in Linguistics 74). Cambridge: Cambridge University Press. Haspelmath, Martin. 1998. Does grammaticalization need reanalysis? Studies in Language $22.2,315-51$.

Heine, Bernd. 2002. On the role of context in grammaticalization. In Ilse Wischer \& Gabriele Diewald (eds.), New reflections on grammaticalisation, 83-102. Amsterdam: John Benjamins. 
Hilpert, Martin. in prep.,2015. Frequencies in diachronic corpora and knowledge of language. In Marianne Hundt, Sandra Mollin \& Simone Pfenninger (eds.), The changing English language: Psycholinguistic perspectives (Studies in English Language). Cambridge: Cambridge University Press.

Hoffmann, Sebastian. 2005. Grammaticalization and English complex prepositions: A corpus-based study (Routledge Advances in Corpus Linguistics 7). London and New York: Routledge.

Huddleston, Rodney \& Geoffrey K. Pullum. 2002. The Cambridge grammar of the English language. Cambridge: Cambridge University Press.

Kay, Paul. 1997. The kind of/sort of construction. Words and the grammar of context (CSLI Lecture Notes 40), 145-58. Stanford CA: CSLI Publications.

Keizer, Evelien. 2007. The English Noun Phrase: The nature of linguistic categorization (Studies in English Language). Cambridge: Cambridge University Press.

Kiparsky, Paul. 2014. New perspectives in historical linguistics. In Claire Bowern \& Bethwyn Evans (eds.), The Routledge handbook of historical linguistics (Routledge Handbooks in Linguistics). Routledge.

Langacker, Ronald W. 1977. Syntactic reanalysis. In Charles N. Li (ed.), Mechanisms of syntactic change, 57-139. Austin TX and London: University of Texas Press.

Leech, Geoffrey. 1981. Semantics: The study of meaning, 2nd edn. Harmondsworth: Penguin. Lieven, Elena V. M. in prep.,2015. Developing language from usage: Explaining errors. In Marianne Hundt, Sandra Mollin \& Simone Pfenninger (eds.), The changing English language: Psycholinguistic perspectives (Studies in English Language). Cambridge: Cambridge University Press. 
Lipka, Leonhard. 1985. Inferential features in historical semantics. In Jacek Fisiak (ed.), Historical semantics. Historical word-formation (Trends in Linguistics. Studies and Monographs 29), 339-54. Berlin, New York and Amsterdam: Mouton.

López Couso, María José. in prep.,2015. xxx. In Marianne Hundt, Sandra Mollin \& Simone Pfenninger (eds.), The changing English language: Psycholinguistic perspectives (Studies in English Language). Cambridge: Cambridge University Press.

Matthews, P. H. 2014. The positions of adjectives in English (Oxford Textbooks in Linguistics). Oxford: Oxford University Press.

Meyerhoff, Miriam. 1992. 'A sort of something' - hedging strategies on nouns. Working Papers on Language, Gender and Sexism 2.1, 59-73.

Parker, Frank. 1976. Language change and the passive voice. Language 52, 449-60.

Quirk, Randolph. 1965. Descriptive statement and serial relationship. Language 41.2, 205-17. Repr. Aarts et al. (2004: Chapter 20, 327-39).

Quirk, Randolph, Sidney Greenbaum, Geoffrey Leech \& Jan Svartvik. 1985. A comprehensive grammar of the English language. London and New York: Longman.

Tabor, Whitney. 1993. The gradual development of degree modifier sort of and kind of: A corpus proximity model. In Katharine Beals et al. (eds.), Papers from the 29th Regional Meeting of the Chicago Linguistic Society, 451-65. Chicago: Chicago Linguistic Society.

Timberlake, Alan. 1977. Reanalysis and actualization in syntactic change. In Charles N. Li (ed.), Mechanisms of syntactic change, 141-77. Austin TX and London: University of Texas Press.

Traugott, Elizabeth Closs. 1999. The role of pragmatics in semantic change. In Jef Verschueren (ed.), Pragmatics in 1998: Selected papers from the 6th International 
Pragmatics Conference, vol. 2, 93-102. Antwerp and Amsterdam: International Pragmatics Association.

Traugott, Elizabeth Closs. in prep.,2015. Low salience as an enabling factor in morphosyntactic change. In Marianne Hundt, Sandra Mollin \& Simone Pfenninger (eds.), The changing English language: Psycholinguistic perspectives (Studies in English Language). Cambridge: Cambridge University Press.

Traugott, Elizabeth Closs \& Richard B. Dasher. 2002. Regularity in semantic change (Cambridge Studies in Linguistics 96). Cambridge: Cambridge University Press.

Traugott, Elizabeth Closs \& Graeme Trousdale. 2013. Constructionalization and constructional changes (Oxford Studies in Diachronic and Historical Linguistics 6). Oxford: Oxford University Press.

Whitman, John. 2001. Relabelling. In Susan Pintzuk, George Tsoulas \& Anthony Warner (eds.), Diachronic syntax: Models and mechanisms. Oxford: Oxford University Press. Whitman, John. 2012. Misparsing and syntactic reanalysis. In Ans van Kemenade \& Nynke de Haas (eds.), Historical linguistics 2009: Selected papers from the 19th International Conference on Historical Linguistics, Nijmegen, 10-14 August 2009 (Current Issues in Linguistic Theory 320), 69-87. Amsterdam and Philadelphia: John Benjamins.

Wood, Frederick T. 1955-6. Verb-adverb combinations: The position of the adverb. English Language Teaching 10, 18-27. 